\title{
Persistence of Neonatal Brachial Plexus Palsy among Nulliparous Versus Parous Women
}

\author{
Rodney A. McLaren Jr., MD ${ }^{1} \quad$ Kate W.-C. Chang, MA, MS ${ }^{2}$ Nana-Ama E. Ankumah, MD ${ }^{3}$ \\ Lynda J.-S. Yang, MD, PhD ${ }^{2}$ Suneet P. Chauhan, MD, Hon. DSc ${ }^{3}$
}

\footnotetext{
1 Department of Obstetrics and Gynecology, Maimonides Medical Center, Brooklyn, New York

${ }^{2}$ Department of Neurosurgery, University of Michigan, Ann Arbor, Michigan

3 Department of Obstetrics, Gynecology and Reproductive Sciences, McGovern Medical School, University of Texas Health Science Center at Houston, Houston, Texas
}

Am J Perinatol Rep 2019;9:e1-e5.

\begin{abstract}
Address for correspondence Suneet P. Chauhan, MD, Division of Maternal Fetal Medicine, Department of Obstetrics, Gynecology and Reproductive Sciences, McGovern Medical School, UT Health Science Center-Houston, 6431 Fannin Street, MSB 3.286, Houston, TX 77030 (e-mail: Suneet.P.Chauhan@uth.tmc.edu).
\end{abstract}

\begin{abstract}
Keywords

- neonatal brachial plexus palsy

- nulliparous

- persistent

- shoulder dystocia

Objective Our objective was to compare persistence of neonatal brachial plexus palsy (NBPP) at 1 and 2 years in children of nulliparous versus parous women.

Study Design We conducted a retrospective cohort study of children diagnosed with NBPP followed at the University of Michigan, Interdisciplinary Brachial Plexus Program (UM-BPP). Self-reported demographics, delivery history, including birth weight (BW) $<$ versus $\geq 9 \mathrm{lbs}$, and presence of shoulder dystocia (SD) were recorded. Student's ttest and Chi-square test with odds ratio (OR) with $95 \%$ confidence intervals $(\mathrm{Cl})$ were calculated for comparisons of maternal, neonatal, and peripartum characteristics. Results Of 337 children with NBPP, 43\% (146) were of nulliparas and 57\% (191) of multiparas. At 1 year, children with persistent NBPP were similar in both groups (87\% vs. $88 \%$, aOR $1.357,95 \% \mathrm{Cl}$ : 0.297-6.208). Persistent NBPP was not significantly different among nulliparous and multiparous women at 2 years $(97 \%$ vs. $92 \%$ respectively, aOR $0.079,95 \% \mathrm{Cl}: 0.006-1.050$ ).

Conclusion In one of the largest cohorts of NBPP, maternal parity did not influence the likelihood of NBPP persistence at 1 and 2 years.
\end{abstract}

Neonatal brachial plexus palsy (NBPP) is defined as weakness or paralysis in an upper extremity of a neonate where the passive range of motion is greater than the active range of motion. ${ }^{1}$ The incidence of NBPP in the United States is approximately 1 to 2 per 1,000 births. ${ }^{1}$ Persistent NBPP, defined as NBPP lasting greater than 12 months, has an incidence in the United States of 1.1 to 2.2 per 10,000 births. $^{2}$

The associated risk factors for NBPP described in the literature include labor abnormalities, fetal macrosomia, operative vaginal delivery, and shoulder dystocia (SD). ${ }^{1}$ However most of these risk factors are unreliable for predicting NBPP. ${ }^{1}$ It has been suggested that parity may be a risk factor for NBPP. Among pregnancies with fetal macrosomia, parous women had a higher incidence of birth trauma compared with nulliparous women. ${ }^{3}$ Also, parous women were found to have double the risk of having a child with NBPP. ${ }^{4}$ In contrast, recent evidence has demonstrated similar rates of NBPP in nulliparas and multiparas. ${ }^{5-7}$ Given conflicting evidence, the primary objective of this retrospective cohort study was to compare persistent NBPP injury diagnosed at 1 and 2 years among nulliparous versus parous women. received

September 18, 2017 accepted after revision November 29, 2018
DOI https://doi.org/

10.1055/s-0038-1677051. ISSN 2157-6998.
Copyright $\odot 2019$ by Thieme Medical Publishers, Inc., 333 Seventh Avenue, New York, NY 10001, USA. Tel: +1(212) 584-4662.
License terms

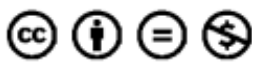




\section{Study Design}

We conducted a retrospective cohort study of patients from the University of Michigan, Interdisciplinary Brachial Plexus Program (UM-BPP) from 2005 to 2015, analyzing records obtained from referring physicians. NBPP was diagnosed and followed at UM-BPP. Charts were reviewed for maternal/ neonatal demographics as well as obstetrical and intrapartum characteristics. Maternal demographics and intrapartum characteristics collected included age, race, gestational age at delivery, diabetes, hypertension, induction/augmentation of labor, duration of labor, mode of delivery, delivery physician, and presence of SD. Neonatal characteristics comprised of gestational age, birth weight (BW), and 5minute Apgar's score.

Presence of torticollis, plagiocephaly, Horner's syndrome, Narakas's classification of NBPP and persistent NBPP were evaluated and diagnosed by the UM-BPP team postnatally. Narakas's group I and II consist of NBPP injuries to the nerve roots $C-5, C-6$, and C-7. Group III and IV consist of injury to C-5, C-6, C-7, C-8, and T-1 resulting in flail arm differentiated with or without presence of Horner's syndrome (IV and III respectively). Persistent NBPP at 1 and 2 years of age was evaluated using active shoulder external rotation and elbow flexion of the affected arm; all shoulder, elbow, hand, and finger range of motion were recorded. Persistence was defined by presence of either musculoskeletal contractures or any joint's active range of motion deviated from normal by $>10$ degrees at 1 and 2 years of age.

Student's $t$-test was used for continuous variables and Chi-square test was performed for categorical variables to assess the associations of maternal, neonatal, and peripartum characteristics between nulliparous and parous women. After exploratory statistics, adjusted odds ratio (aOR) for maternal age, ethnicity, gestational diabetes, operative vaginal delivery, SD, BW, and referral age were calculated using multiple logistic regressions along with 95\% confidence intervals (CI) calculated for comparisons of persistent NBPP between the two groups of parity. Analysis was performed using Stata version 13.1 (College Station, TX). A $p$-value $<0.05$ was considered statistically significant.

\section{Results}

A total of 337 charts of patients with NBPP at UM-BPP were included in the data analysis. The maternal demographic characteristics are presented in -Table 1. Nulliparous women were younger compared with multiparous women $(p<0.001)$. Race, gestational age at delivery, diabetes, and hypertension were similar between the two groups.

-Table 2 demonstrates the associations of peripartum factors between the nulliparous and multiparous women. Nulliparous women had longer labor and were more likely to have an operative delivery compared with multiparous women ( $p<0.001$ and $p<0.003$, respectively). Location of delivery, cephalic presentation, and the delivering provider were similar between the two groups. There were a total of 10 home deliveries (five in each group) and four noncephalic presentations (two in each group). SD was not significantly different between nulliparous and multiparous women ( $64 \%$ vs. $70 \%, p=0.24)$. Children of nulliparous women were more likely to be smaller compared with those of multiparous women ( $30 \%$ vs. $53 \%, p<0.001)$. Other neonatal characteristics were similar between the nulliparous and multiparous groups.

Affected children's demographics are presented in -Table 3. Children of nulliparous women were referred at an earlier age ( 3 vs. 3.7 months, $p=0.049$ ) to the UM-BPP clinic. There was no significant difference between the two groups in regard to the children's gender, household income, and treatment of NBPP.

Table 1 Maternal demographics

\begin{tabular}{|l|l|l|l|l|}
\hline Variable & $\begin{array}{l}\text { Entire cohort } \\
(\boldsymbol{n}=337)\end{array}$ & $\begin{array}{l}\text { Nulliparous } \\
(\boldsymbol{n}=146)\end{array}$ & $\begin{array}{l}\text { Parous } \\
(\boldsymbol{n}=\mathbf{1 9 1})\end{array}$ & $p$-Value \\
\hline Maternal age (y) & & & & $<0.0001$ \\
\hline$<20$ & $21 / 299(7 \%)$ & $21 / 133(16 \%)$ & $0 / 166(0 \%)$ & \\
\hline$\geq 35$ & $60 / 299(20 \%)$ & $11 / 133(8 \%)$ & $49 / 166(30 \%)$ & \\
\hline Race & & & & 0.06 \\
\hline White & $226 / 315(72 \%)$ & $106 / 133(80 \%)$ & $120 / 182(66 \%)$ & \\
\hline African American & $59 / 315(19 \%)$ & $16 / 133(12 \%)$ & $43 / 182(24 \%)$ & \\
\hline Others & $30 / 315(10 \%)$ & $11 / 133(8 \%)$ & $19 / 182(10 \%)$ & \\
\hline Diabetes & $74 / 316(23 \%)$ & $28 / 139(20 \%)$ & $46 / 177(26 \%)$ & 0.22 \\
\hline Hypertension & $55 / 308(18 \%)$ & $27 / 134(20 \%)$ & $28 / 174(16 \%)$ & 0.36 \\
\hline $\begin{array}{l}\text { Household income, U.S. } \\
\text { S; median (range) }\end{array}$ & $46,636(12,262-123,771)$ & $46,827(12,262-123,771)$ & $46,484(12,262-123,771)$ & 0.87 \\
\hline Prior SD & $21 / 196(11 \%)$ & 0 & $21 / 173(12 \%)$ & - \\
\hline
\end{tabular}

Abbreviation: SD, shoulder dystocia.

Denominators displayed when missing data. 
Table 2 Evaluation of association of peripartum factors with mother's parity

\begin{tabular}{|c|c|c|c|c|}
\hline & $\begin{array}{l}\text { Entire cohort } \\
(n=337)\end{array}$ & $\begin{array}{l}\text { Nulliparous } \\
(n=146)\end{array}$ & $\begin{array}{l}\text { Parous } \\
(n=191)\end{array}$ & p-Value \\
\hline Labor location & & & & 0.70 \\
\hline Hospital & $317 / 327(97 \%)$ & $139 / 144(97 \%)$ & $178 / 183(97 \%)$ & \\
\hline Home & $10 / 327(3 \%)$ & $5 / 144(3 \%)$ & $5 / 183(3 \%)$ & \\
\hline Gestational age, wk $^{a}$ & $39(2)$ & $39(2)$ & $39(1)$ & 0.90 \\
\hline Cephalic presentation & $324 / 328(99 \%)$ & $142 / 144(99 \%)$ & $182 / 184(99 \%)$ & 0.81 \\
\hline Induction/augmentation of labor & $182 / 303(60 \%)$ & $87 / 137(64 \%)$ & $95 / 166(57 \%)$ & 0.27 \\
\hline Duration of labor, $\mathrm{h}^{\mathrm{a}}$ & $13(11)$ & $16(11)$ & $11(10)$ & $<0.0001$ \\
\hline Operative delivery (vacuum or forceps) & $71 / 312(23 \%)$ & $42 / 137(31 \%)$ & $29 / 175(17 \%)$ & 0.003 \\
\hline Delivery physician & & & & 0.60 \\
\hline OB/GYN & $305 / 330(92 \%)$ & $132 / 145(91 \%)$ & $173 / 185(94 \%)$ & \\
\hline Midwife & $16 / 330(5 \%)$ & $9 / 145(6 \%)$ & $7 / 185(4 \%)$ & \\
\hline Family practice & $9 / 330(3 \%)$ & $4 / 145(3 \%)$ & $5 / 185(3 \%)$ & \\
\hline Shoulder dystocia with current birth & $208 / 308(68 \%)$ & $85 / 133(64 \%)$ & $123 / 175(70 \%)$ & 0.24 \\
\hline Birth weight $>9$ lbs. & $142 / 331(43 \%)$ & $42 / 142(30 \%)$ & $100 / 189(53 \%)$ & $<0.0001$ \\
\hline Apgar's score $<7$ at 5 min & $29 / 170(17 \%)$ & $11 / 77(14 \%)$ & $18 / 93(19 \%)$ & 0.38 \\
\hline Clavicle fracture & $31 / 327(9 \%)$ & $12 / 141(9 \%)$ & $19 / 186(10 \%)$ & 0.60 \\
\hline Humerus fracture & $22 / 326(7 \%)$ & $8 / 140(6 \%)$ & $14 / 186(8 \%)$ & 0.52 \\
\hline
\end{tabular}

Abbreviation: OB, obstetricians; GYN, gynecologists.

Denominators displayed when missing data.

amean (standard deviation).

Table 3 Children's characteristics and outcomes

\begin{tabular}{|l|l|l|l|l|}
\hline Variable & $\begin{array}{l}\text { Entire cohort } \\
(\boldsymbol{n}=337)\end{array}$ & $\begin{array}{l}\text { Nulliparous } \\
(\boldsymbol{n}=146)\end{array}$ & $\begin{array}{l}\text { Parous } \\
(\boldsymbol{n}=191)\end{array}$ \\
\hline Child's gender & & & & 0.98 \\
\hline Male & $159(47 \%)$ & $69(47 \%)$ & $90(47 \%)$ \\
\hline Female & $178(53 \%)$ & $77(53 \%)$ & $101(53 \%)$ & $3.7(0-384)$ \\
\hline Referral age, mo ${ }^{\text {a }}$ & $3.2(0-384)$ & $3(0-144)$ & $72(38 \%)$ & 0.049 \\
\hline Torticollis & $142(42 \%)$ & $70(48 \%)$ & $43(23 \%)$ & 0.06 \\
\hline Plagiocephaly & $93(28 \%)$ & $50(34 \%)$ & $22(12 \%)$ \\
\hline Horner's syndrome & $44(13 \%)$ & $20(14 \%)$ & & 0.02 \\
\hline Narakas's & & & $81 / 152(53 \%)$ \\
\hline Grade I-II & $145 / 272(53 \%)$ & $64 / 120(53 \%)$ & $71 / 152(47 \%)$ \\
\hline Grade III-IV & $127 / 272(47 \%)$ & $56 / 120(47 \%)$ & & 0.55 \\
\hline Treatment & & & $27 / 165(16 \%)$ \\
\hline Nerve surgery & $49 / 299(16 \%)$ & $22 / 134(16 \%)$ & $11 / 161(7 \%)$ \\
\hline Botulinum toxin & $19 / 294(6 \%)$ & $8 / 133(6 \%)$ & $21 / 165(13 \%)$ \\
\hline Shoulder surgery & $35 / 299(12 \%)$ & $14 / 134(10 \%)$ & $7 / 167(4 \%)$ & 0.99 \\
\hline Other orthopaedic surgery & $10 / 301(3 \%)$ & $3 / 134(2 \%)$ & 0.78 \\
\hline
\end{tabular}

Denominators displayed when missing data.

${ }^{\mathrm{a}}$ Median (range). 
Table 4 Association of persistent NBPP with mother's parity

\begin{tabular}{|c|c|c|c|c|}
\hline & $\begin{array}{l}\text { Nulliparous } \\
(n=146)\end{array}$ & $\begin{array}{l}\text { Parous } \\
(n=191)\end{array}$ & $\begin{array}{l}\text { aOR } \\
(95 \% \mathrm{Cl})\end{array}$ & $\begin{array}{l}p- \\
\text { Value }\end{array}$ \\
\hline $\begin{array}{l}\text { Persistent } \\
\text { NBPP at } 1 \text { y }\end{array}$ & $\begin{array}{l}127 \\
(87 \%)\end{array}$ & $\begin{array}{l}164 / 187 \\
(88 \%)\end{array}$ & $\begin{array}{l}1.357 \\
(0.297- \\
6.208)\end{array}$ & 0.69 \\
\hline $\begin{array}{l}\text { Persistent } \\
\text { NBPP at } 2 \text { y }\end{array}$ & $\begin{array}{l}90 / 93 \\
(97 \%)\end{array}$ & $\begin{array}{l}121 / 131 \\
(92 \%)\end{array}$ & $\begin{array}{l}0.079 \\
(0.006- \\
1.050)\end{array}$ & 0.05 \\
\hline
\end{tabular}

Abbreviation: aOR, adjusted odds ratio; $\mathrm{Cl}$, confidence interval; NBPP, neonatal brachial plexus palsy.

Denominators displayed when missing data.

Persistence of NBPP in the nulliparous versus multiparous women is exhibited in - Table 4 . The persistence of NBPP at 1 year was similar between nulliparous and parous women (87 vs. $88 \%$, aOR: $1.357,95 \%$ Cl: $0.297-6.208, p=0.694$ ). At 2 years, NBPP was not more likely to be persistent in the nulliparous group compared with parous group (97 vs. $92 \%$, aOR: $0.079,95 \% \mathrm{CI}: 0.006-1.05, p=0.054$ ).

\section{Discussion}

This study demonstrated that persistence of NBPP at 1 and 2 years was similar among nulliparous and parous women. Prior investigations demonstrated conflicting results. Boyd et al reported a higher incidence of a composite of neonatal birth trauma, which included brachial plexus injury among parous women compared with nulliparous women with fetal macrosomia, which was defined as $>4,000$ grams, in both groups. ${ }^{3}$ Similarly, parous women were found to have double the risk of having a child with NBPP compared with nulliparous women. ${ }^{4}$ Conversely, parity was found not to be a risk factor in a case control study of 45 consecutive Erb's palsy cases. ${ }^{5}$ Furthermore, a recent case series demonstrated the rates of NBPP were similar between nulliparous and parous women regardless of BW. ${ }^{7}$ Summary of these studies are shown in - Table 5 .
The most common and significant association of NBPP reported in the literature is SD, with which NBPP occurs in $50 \%$ of such cases. ${ }^{1}$ SD had previously been shown to occur in nearly all permanent NBPP examined, ${ }^{8,9}$ though recent evidence has shown this may not be the case. ${ }^{6,10}$ As seen in our results, SD was not significantly different between nulliparous and parous women in this cohort, and thus should not be considered a confounding factor when evaluating the role of parity in permanent NBPP.

Fetal macrosomia, defined as $\geq 4,500$ grams, is a predictor of NBPP. ${ }^{11}$ Though neonates born to nulliparous women were less often macrosomic compared with neonates from parous women, no difference was seen in the persistence of NBPP at 1 and 2 years. A similar outcome has been previously described where more than half of the cases (37 of 63) of permanent NBPP occurred in infants with a BW less than 4,500 grams. $^{9}$ In another retrospective review, Ouzounian et al demonstrated that only 9 out of 97 cases of BPP had fetal macrosomia. $^{6}$

Another important risk factor, although not proven to be a predictor of occurrence, is operative vaginal delivery. ${ }^{1}$ Nath et al reported that in 239 permanent NBPP patients $41 \%$ were delivered via instrumental delivery. ${ }^{8}$ Another study reported $21 \%$ of 63 permanent NBPP had an operative delivery. ${ }^{9}$ Although operative vaginal delivery occurred more often in nulliparous women compared with parous women in this study (31 and $17 \%$, respectively), there was no significant difference in the persistence of NBPP at 1 and 2 years between the two groups.

There are limitations of our study. Data were retrospectively collected and the reports of antenatal characteristics were obtained from maternal report, thus increasing the chance of recall bias. We were unable to obtain obstetrical medical records, as collection of this information following the care of the infant would have been strictly for research purposes, thus necessitating approval of institutional review board from every institution from which the mothers were managed. Since this cohort is derived from referrals, we may not have captured all of the NBPP as the neonates with NBPP that resolved soon after delivery may not have been referred.

Table 5 Prior publications on parity and NBPP

\begin{tabular}{|c|c|c|c|c|c|c|}
\hline Reference & $\begin{array}{l}\text { Total } \\
\text { women } \\
\text { studied (n) }\end{array}$ & $\begin{array}{l}\text { Rate of NBPP } \\
\text { (per } 1,000 \\
\text { births) }\end{array}$ & $\begin{array}{l}\text { NBPP followed } \\
\text { for } \geq 1 \text { y by }\end{array}$ & $\begin{array}{l}\text { NBPP nulliparous } \\
\text { women } n \text { (per } \\
1,000 \text { births) }\end{array}$ & $\begin{array}{l}\text { NBPP multiparous } \\
\text { women } n \text { (per } \\
1,000 \text { births) }\end{array}$ & $\begin{array}{l}\text { Reported } \\
\text { significance }\end{array}$ \\
\hline Boyd et $\mathrm{al}^{3}$ & 1,897 & 8 & Unknown & $2 / 640(3)$ & 13/1,257 (10) & Not reported \\
\hline Weizsaeckeret al $^{5}$ & 135 & 4.1 & Unknown & $16 / 57(28)$ & $29 / 78(37)$ & NS \\
\hline Lindqvist et $\mathrm{al}^{4}$ & 1,168 & 3.2 & $\begin{array}{l}\text { Hand surgeon, } \\
\text { regular } \\
\text { follow-up for } \\
\text { up to } 1 \text { y }\end{array}$ & $54 / 555(97)$ & $114 / 613(186)$ & OR $2.0-2.4^{a}$ \\
\hline Ouzounian et al ${ }^{6}$ & 13,998 & 6 & Unknown & $24 / 4,034(6)$ & $69 / 9,930(7)$ & NS \\
\hline Clapp et $\mathrm{al}^{7}$ & 152 & 1 & Unknown & $30 / 66(454)$ & $46 / 86(535)$ & NS \\
\hline
\end{tabular}

Abbreviation: $\mathrm{Cl}$, confidence interval; NBPP, neonatal brachial plexus palsy; NS, not significant; OR, odds ratio.

${ }^{a}$ Odds ratio varied by parity: nullipara referenced 1 vs. Para 1, OR: 2.0, 95\% Cl: 1.4-2.9; Para 2, OR: 2.2, 95\% Cl: 1.3-3.7; Para $\geq 3$, OR: $2.4,95 \% \mathrm{Cl}$ : 1.4-4.1. 
However, the median referral age was at 3 months of life in this cohort which is a time when persistence or resolution cannot be predicted, thus significant bias should not exist in either direction. We also had no reason to believe that there would be a bias that neonates of parous women would be more or less likely to have been referred compared with nulliparous women.

There are many strengths to this publication. This study embodies one of the largest cohorts of patients diagnosed with NBPP ( $n=337)$ that have long-term follow-up. These children are also from a single center and thus have homogeneity in diagnosis and treatment.

\section{Conclusion}

In conclusion, parity does not influence the likelihood of persistence of NBPP. In spite of this being one of the largest cohorts of NBPP, we were unable to establish that knowledge of obstetrical history or risk factors associated with NBPP has clinical benefit in preventing NBPP or predicting its persistence.

\section{Note}

Presented as a poster presentation at Central Association of Obstetricians and Gynecologists; Las Vegas, Nevada, October 27-28, 2016.

Funding

The authors do not report any financial disclosures.

\section{Conflict of Interests}

None declared.

\section{References}

1 The American College of Obstetricians and Gynecologists. Neonatal Brachial Plexus Palsy. Washington DC: ACOG; 2014

2 Chauhan SP, Blackwell SB, Ananth CV. Neonatal brachial plexus palsy: incidence, prevalence, and temporal trends. Semin Perinatol 2014;38(04):210-218

3 Boyd ME, Usher RH, McLean FH. Fetal macrosomia: prediction, risks, proposed management. Obstet Gynecol 1983;61(06):715-722

4 Lindqvist PG, Erichs K, Molnar C, Gudmundsson S, Dahlin LB. Characteristics and outcome of brachial plexus birth palsy in neonates. Acta Paediatr 2012;101(06):579-582

5 Weizsaecker K, Deaver JE, Cohen WR. Labour characteristics and neonatal Erb's palsy. BJOG 2007;114(08):1003-1009

6 Ouzounian JG, Korst LM, Miller DA, Lee RH. Brachial plexus palsy and shoulder dystocia: obstetric risk factors remain elusive. Am J Perinatol 2013;30(04):303-307

7 Clapp MA, Bsat J, Little SE, Zera CA, Smith NA, Robinson JN. Relationship between parity and brachial plexus injuries. J Perinatol 2016;36(05):357-361

8 Nath RK, Kumar N, Avila MB, et al. Risk factors at birth for permanent obstetric brachial plexus injury and associated osseous deformities. ISRN Pediatrics 2012;2012:307039

9 Ouzounian JG, Korst LM, Phelan JP. Permanent Erb's palsy: a lack of a relationship with obstetrical risk factors. Am J Perinatol 1998;15 (04):221-223

10 Chang KW, Ankumah NA, Wilson TJ, Yang LJ, Chauhan SP. Persistence of neonatal brachial plexus palsy associated with maternally reported route of delivery: review of 387 cases. Am J Perinatol 2016;33(08):765-769

11 American College of Obstetricians and Gynecologists' Committee on Practice Bulletins-Obstetrics. Practice bulletin no. 173: fetal macrosomia. Obstet Gynecol 2016;128(05):e195-e209

This article has been updated as per the erratum published on April 4, 2019; doi: 10.1055/s-0039-1687855. The page numbers have been updated to e1-e5. 